\title{
How Elephants are Opening Doors: Developmental Neuroethology, Attachment and Social Context
}

\author{
G. A. Bradshaw*† \& Allan N. Schore $\ddagger$ \\ * Kerulos Centre for Animal Psychology and Trauma Recovery \\ $\dagger$ Pacifica Graduate Institute, Carpinteria, CA, USA \\ ¥ Department of Psychiatry and Biobehavioural Sciences, David Geffen School of Medicine, University of California at Los Angeles, Los Angeles, \\ CA, USA \\ $\S$ UCLA Center for Culture, Brain, and Development, Northridge, CA, USA
}

\author{
Correspondence \\ G.A. Bradshaw, 800 Beavercreek Road, \\ Jacksonville, OR 97530, USA. \\ E-mail: gay.bradshaw@orst.edu \\ Received: July 27, 2006 \\ Initial acceptance: September 7, 2006 \\ Final acceptance: November 10, 2006 \\ (S.K. Sakaluk) \\ doi: 10.1111/j.1439-0310.2007.01333.x
}

\begin{abstract}
Ethology's renewed interest in developmental context coincides with recent insights from neurobiology and psychology on early attachment. Attachment and social learning are understood as fundamental mechanisms in development that shape core processes responsible for informing behaviour throughout a lifetime. Each field uniquely contributes to the creation of an integrated model and encourages dialogue between Tinbergen's four analytical levels: ethology in its underscoring of social systems of behaviour and context, psychology in its emphasis on socioaffective attachment transactions, and neuroscience in its explication of the coupled development of brain and behaviour. We review the relationship between developmental context and behaviour outcome as a topic shared by the three disciplines, with a specific focus on underlying neuroethological mechanisms. This interdisciplinary convergence is illustrated through the example of abnormal behaviour in wild African elephants (Loxodonta africana) that has been systematically observed in human-caused altered social contexts. Such disruptions impair normative socially mediated neuroendocrinological development leading to psychobiological dysregulation that expresses as non-normative behaviour. Aberrant behaviour in wild elephants provides a critical field example of what has been established in ex situ and clinical studies but has been largely absent in wild populations: a concrete link between effects of human disturbance on social context, and short- and longterm neuroethology. By so doing, it brings attention to the significant change in theories of behaviour that has been occurring across disciplines - namely, the merging of psychobiological and ethological perspectives into common, cross-species, human inclusive models.
\end{abstract}

\section{Introduction}

Recalling Niko Tinbergen, a number of authors are now encouraging renewed interdisciplinary efforts in the analysis of behaviour (Linklater 2004; Taborsky 2006). Tinbergen considered that consideration of all four analytical levels informing behaviour - evolu- tion, development, causation, and function - was necessary to create conceptual and methodological coherency (Tinbergen 1963). Along these lines, Bateson (2003) suggests that ethology should return to Tinbergen's 'how' and 'why' questions: to fundamental problems of understanding mechanisms involved in the development and control of 
behaviour. Citing developmental neuroscience studies on social learning (learning from observing another's behaviour) in early brain development, Bateson calls for an integrated approach to behavioural biology to study the features of the stimuli that start off the formation of the social attachment [and] the establishment of a representation of that combination of features and the linking of such a representation to the system controlling social behaviour' (Bateson 2003, p. 12).

Ethology is not alone in its renewed interest in attachment (i.e. caregiver-infant bonding; Stamps 2003). Over the past decade, psychology and neuroscience have intensively studied the links between attachment and their neural substrates. This focus has created unifying models of developmental neuroethology for humans and animals. It has also contributed to significant changes in how development and behaviour are understood (Davidson et al. 2003). Together, ethology, psychology, and neuroscience appear to be converging on trans-species models of brain and behaviour.

Each field brings a critical dimension to understanding how developmental context contributes to particular behavioural outcomes: ethology in its underscoring of social systems of behaviour and contexts (e.g. ontogenetic niche; West \& King 1987), psychology in its emphasis on socio-affective attachment transactions (e.g. Schore 1994), and neuroscience in its explication of the coupled development of brain and social behaviour (e.g. Sapolsky 2004; Curley \& Keverne 2005). Here, we review the relationship between attachment and behaviour outcomes at this interdisciplinary confluence with emphasis on underlying neuroethological mechanisms.

The opportunity to illustrate this disciplinary intersection comes from a somewhat unanticipated source: atypical behaviour and developmental compromise in wild African elephants. Since the 1990s, significant changes from statistically normative behaviour of wild elephants have been observed and linked to stressors that disrupt social processes: culls (systematic killing to control populations), poaching, herd manipulation, habitat fragmentation, and translocation (Slotow et al. 2000; Bradshaw et al. 2005; Owens \& Owens in press). While developmental contexts and the effects of social disruptions on behaviour are extensively documented for multiple species in clinical and ex situ studies (Silk et al. 2003; Topal et al. 2005), what has not been studied or hitherto observed except for the most part as anecdotal, are these phenomena in free-ranging species. Excluding a few exceptions (e.g. primate infanticide; Hausfater \& Blaffer Hrdy 1984), abnormal behaviour in the wild is sparsely studied.

Integrating ethology and psychology is nothing novel. Tinbergen himself spoke about the two disciplines differing mainly in focus (Tinbergen 1951) and the seminal work on attachment by psychiatrist John Bowlby (1969) drew directly from ethology. However, until recently, drawing formal inferences from humans and extending them to animals has been judged at best, speculative (although exceptions exist; see Wrangham et al. 2006). By in large, cognitive and affective elements underlying human behaviour models have been considered lacking in other species. New ethological data, brain imaging research, and an understanding of the evolutionary conservation of brain structures and mechanisms have lifted this restriction and lead to species-inclusive models (Berridge 2003; Bradshaw \& Finlay 2005; Bradshaw \& Sapolsky 2006). Species differences remain and not all issues surrounding comparative study are erased. However, increasingly, the use of a common vertebrate model is assumed where species differences are only noted when deemed significant (a convention that we follow here).

The primary goal of this review is to describe the coalescence of theories of behaviour across disciplines and the emergence of trans-species models of brain and behaviour. The neuroethological analysis of non-normative elephant behaviour here illustrates how integrative models of psychobiology and ethology find congruence with what we already know about core psychophysiological homologies among all mammals (and birds, see Jarvis et al. 2005). Aggression (Blanchard \& Blanchard 1984) and attachment (Schore 2003a,b), both key elements in the elephant narrative, are specific examples where such cross-species research is well established. What may have appeared in the past as behavioural isolates, now make up the fabric of a coherent conceptual framework for describing both humans and animals.

\section{Social Context and Developmental Mechanisms}

Altricial avian and mammalian young are immersed in a social environment. Parents or alloparents (a set of caretaking affiliated siblings and adults; Lee 1987) provide the primary external source of sensory input and regulation of all essential developmental processes that interact with genetics and greater environmental conditions (West et al. 2003). Communication 
modalities of smell, taste, touch, vision, and sound and socio-affective interactions form the sensory matrix in which the infant is embedded, and from which the infant learns how to function (Goldstein et al. 2003). How an organism initially develops in this context affects individual viability and adaptation success over the rest of the life span (Schore 1994).

Sociality, of which attachment is a central feature, is envisioned as an evolutionary strategy to help maximize fitness in the face of complex social and environmental variability (Dunbar 1998). Details of social exchange reflect successful adaptations necessary for infant survival through the process of maturation. What and how an individual learns is specific to their species and anticipated environmental demands. However, there is a great deal of flexibility in what and how traits are expressed. Individual survival and mortality depend on variations in rearing behaviour, demographics and environmental surround (Ha et al. 1999) which in turn influence if, and to what degree, genetics are expressed (Sapolsky 2004; Curley \& Keverne 2005).

Attachment is typically the first stage in socialization (Bowlby 1969). Early social contexts are comprised of multiple dynamic processes having the potential for positive or negative values in terms of ecological and evolutionary significance (Stamps 2003). Elephant matriarch age, associated with enhanced contexts, is a significant predictor of the number of calves produced by the family (McComb et al. 2001). Levels and quality of sociality among adult females has been positively correlated with infant survival in primates and other species (e.g. elephants; Lee 1987; baboons; Silk et al. 2003). Socialization quality influences fitness by affecting infant protection, stress levels, resource mobilization, and socio-ecological knowledge (Mesnick 1997). It is now established that elephants, like humans, great apes, and dolphins, show highly complex behaviours such as self-awareness (mirror self-recognition; Plotnik et al. 2006), an outcome of optimal attachment bonding and right brain development (Schore 1994).

Social disruptions exceeding a certain level diminish fitness by decreasing the efficacy of social bond functions. Stressors that diminish parent-infant transactions or cause parental energy to divert from foraging, mating, infant care and group participation (e.g. ecotourism, noise, perceived threats by hunters) are one example (Fowler 1999; Burke 2005). Neglectful, stressed or abusive maternal behaviour, hyper-aggression, exaggerated fearfulness, infant abandonment, spontaneous abortions, and infanti- cide are stress-related behaviour that contribute to fitness and population declines (Ha et al. 1999; Silk et al. 2003; Owens \& Owens in press). Significantly, social context and environmental quality directly map to neurobiological patterns and processes in developing offspring as well as adults (Schore 2003a,b).

Vertebrates, and mammals in particular, share common socially mediated brain and behavioural development patterns (Berridge 2003). Cortical and limbic structures responsible for processing and controlling emotional and social information and associated psychophysiological and behavioural traits (e.g. maternal behaviour, facial recognition, play, sexual behaviour, fear, aggression and affect regulation) are all highly conserved evolutionarily across species (Panksepp 1998; Fleming et al. 1999).

Mammalian brain development is experience dependent and highly sensitive to environmental change (Meaney 2001). Transactions between caregivers and offspring guide a finely tuned dialogue between social and neurobiological processes. In conjunction with the infant's own autonomic nervous system (ANS), these exchanges serve as primary regulatory mechanisms that govern behaviour throughout life. Socially dominated development coincides with periods of rapid brain growth and shaping of evolving affective and neuroendocrinological self-regulatory systems (Siegel 1999; Helmeke et al. 2001). Not only does the caregiver's behaviour guide the infant's stress responses through neuroethological patterning, but does so through tissuespecific effects on gene expression (Meaney \& Szyf 2005).

Early social context parameters directly influence one of the most fundamental structures in behaviour regulation - the hypothalamic-pituitary-adrenal (HPA) axis. Repeated HPA axis activation and associated elevated endogenous corticosteroids effected through stress can impair gene expression involved in neurogenesis and synaptogenesis (Karten et al. 2005) and compromise postnatally maturing brain circuits involved in mnemonic, cognitive and affective regulatory functions (Ladd et al. 2004). Traumatic disruption from a single threatening event alone can create life-long changes in social learning abilities and neural organization (Wiedenmayer 2004). Direct (e.g. death of mother) or indirect (e.g. transmitted maternal stress; Francis et al. 1999) compromise can induce sustained effects on brain plasticity and create a structural vulnerability for psychopathogenesis and early death (Heim \& Nemeroff 1999; Cirulli et al. 2003). 
Cross-species studies also show that early rearing conditions affect hemispheric development (Ronsaville et al. 2006). Specifically, neonatal social behaviour associated with the HPA axis increases right hemisphere dominance (Tang et al. 2003). Preferential hemispheric development is significant because postnatally maturing orbital prefrontal areas in the early developing (Chiron et al. 1997) right brain are centrally involved in attachment, emotion, stress regulation, and the control of social behaviour (Chiron et al. 1997; Henry 1993; Lyons et al. 2002; Sullivan \& Dufresne 2006). Early attachment trauma is 'affectively burnt in' the hierarchical apex of the limbic system and the HPA axis, the right frontal lobe (Stuss \& Alexander 1999). Altered sociality therefore translates to altered patterns in core survival functions that govern coping behaviour and stress regulation abilities. Further, by such mechanisms, relational stress during gestational and postnatal periods can transmit to offspring (Dettling et al. 2002).

Stress effects manifest both intra-organismically (e.g. increased vulnerability to disease) and inter-organismically (e.g. asocial and atypical affiliative behaviours) through triggering hyperarousal in the limbic and ANSs that support emotional behaviour. This is biochemically expressed in elevated levels of arousal regulating catecholamines, corticotropinreleasing factor, and corticosteroids and behaviourally in one or more ways: a persistent fearful temperament (Adolphs et al. 2004), diminished capacity to modulate memory, fear, and social judgement (Morris, Ohman $\&$ Dolan 1999), a predisposition to aggression dysregulation and violence (Rohlfs \& Ramirez 2006), and post-traumatic stress disorder (PTSD; Schore 2003a). Resulting impairment of socio-affective circuits, especially in higher cortical regions, underlies many abnormal and inappropriate emotional responses that express at later stages of life (Poeggel et al. 2005).

Beyond altered behaviour and biology of the affected individual, early experiences link evolutionarily. For example, epigenetic mechanisms contributing to brain lateralization and hemispheric specialization can offer an evolutionary advantage in survival (Vallortigara \& Rogers 2005). Ecological and evolutionary fitness are directly related to early relational quality through the shaping of neuroendocrinological pathways. As recent $\mathrm{G} \times \mathrm{E}$ (gene-environment interactions) research indicates (Suomi 2004; Curley $\delta$ Keverne 2005), inheritance and experience are intertwined and parental care is revealed as a critical agent of natural selection that influences the stabilization or elimination of corticolimbic connections during early periods. In summary, a psychobiological perspective reveals that stress and changes in normative patterns of sociality can have far-reaching consequences leading to maladaptive responses to environmental cues later in life and transmit across generations (Ichise et al. 2006; McCormack et al. 2006).

\section{Altered Social Context Effects in Wild Elephants}

Elephant social contexts are organized in nested sets of sustained relationships revolving around a natal family composed of a matriarch and female allomothers (Lee 1987). After weaning, females remain in the natal herd learning how to care for younger herd members, while young males, between the ages of 9 and $18 \mathrm{yr}$, leave and enter a second phase of socialization in the company of an all-bull group or area (Lee \& Moss 1999).

In contrast to historical patterns and locales today such as Amboseli, Kenya, where herd structure is relatively intact, elephant social contexts are extremely altered as a result of anthropogenic disturbances (Poole 1989; Nyakaana et al. 2001). Starvation, culls, poaching, habitat reduction and isolation, and translocations have significantly changed traditional socialization patterns and skewed elephant demographics (Poole 1989; Abe 1994). DNA studies show that selective hunting of older members has been so extensive to cause genetic shifts (Nyakaana et al. 2001). In North Luangwa National Park, Zambia, 93\% of the population has been killed and allomothers are largely absent. Females reproduce at much younger ages $(48 \%$ of the births were by females <14 yr compared with a normative mean age of first birth at $16 \mathrm{yr})$. Group size and composition have drastically altered: $36 \%$ of groups have no adult females, one quarter of the units consists only of a single mother and calf, and $7 \%$ of groups are sexually immature orphans (Owens \& Owens 2005, in press). In Mikumi, Tanzania, $72 \%$ of the population was similarly affected and in Uganda, elephants live in semi-permanent aggregations of over 170 animals with many females between the ages of 15 and 25 yr having no familial association or hierarchical structure (Poole 1989; Aleper \& Moe 2006). Infants are largely reared by inexperienced, highly stressed, single mothers without the socio-ecological knowledge, leadership, and support that a matriarch and allomothers provide (Slotow \& van Dyk 2001; Owens \& Owens in press).

Accompanying these changes, elephants are exhibiting uncharacteristic behaviours and elevated 
stress (Table 1). Most astounding and statistically significant, have been the killing of white (Diceros bicornis) and black (Ceratotherium simu) rhinoceroses (Slotow et al. 2000). Between 1991 and 2001, young male elephants killed 58 white rhinoceroses and five black rhinoceroses in Hluhluwe-Umfolozi National Park (HUP) and from 1992 and 199649 white rhinoceroses in Pilanesberg National Park (PNP: Slotow et al. 2001). Prior to these elephantcaused deaths, median rhinoceros mortality was estimated at three per year (Slotow $\&$ van Dyk 2001). In both parks, elephant demographics were very skewed. For instance, in HUP all of the 12 males were $<14 \mathrm{yr}$ of age. In addition to the killing, young males were observed to attempt copulation with some of the rhinoceroses. No particular factor could be ascribed to the rhinoceroses that might have led to the killings (Slotow et al. 2001; Slotow \& van Dyk 2001).

Non-normative elephant behaviour not unknown, but it has been regarded as a condition of psychophysiological stress of captivity. Infant rejection and neglect, elevated intraspecies and interspecies dysregulated aggression, anhedonia, depression, a suite of socio- and psychopathologies, distress vocalizations, movements, immunosuppression, and elevated cortisol levels are well documented (Brown et al. 2005). Now such behaviours associated with attachment disorders and symptoms characteristic of stress response dysregulation in vertebrates are increasingly observed in the wild (Slotow et al. 2000, 2001; Garaï et al. 2004).

Historically, intraspecies and interspecies violence is uncommon (Hanks 1979). Even during musth (when male elephants exhibit elevated aggression and high levels of testosterone and temporal gland secretion), male-male injury and mortality are relatively rare (AERP 2006). In Amboseli, mortality data over several decades reveal only three cases $(6.1 \%)$ of adult (>12 yr) male-male killings out of 49 incidences where the cause of death was known. In contrast, significant intraspecific aggression is present where elephants have developed under highly irregular herd structures and confinement. For example, an intraspecific mortality of $70-90 \%$ of adult male elephant deaths has been recorded in Addo Elephant National Park, South Africa (Whitehouse \& Kerley 2002). Other indicators associated with intense socio-ecological disturbance including broken tusks, puncture wounds and elevated corticosteroid metabolite concentrations have also been observed (Foley et al. 2001).

Table 1: Elephant developmental context alterations and associated behaviour (eight locations in Africa)

\begin{tabular}{|c|c|c|c|}
\hline Location & Behaviour & $\begin{array}{l}\text { Altered developmental context } \\
\text { alteration and associated stressor }\end{array}$ & Reference \\
\hline $\begin{array}{l}\text { Pilanesberg National Park } \\
\text { (PNP), SA }\end{array}$ & $\begin{array}{l}\text { Interspecies hyper-aggression, } \\
\text { non-consensual interspecies sex, } \\
\text { and mortality; decreased affiliative } \\
\text { behaviour }\end{array}$ & $\begin{array}{l}\text { Cull, translocation, inadequate herd } \\
\text { structure, premature weaning }\end{array}$ & $\begin{array}{l}\text { Slotow et al. (2000), Slotow \& } \\
\text { van Dyk (2001), Garaï et al. } \\
\text { (2004) }\end{array}$ \\
\hline $\begin{array}{l}\text { Hluhluwe-Umfolowzi } \\
\text { National Park (HUP), SA }\end{array}$ & $\begin{array}{l}\text { Interspecies hyper-aggression, } \\
\text { non-consensual interspecies sex, } \\
\text { and mortality }\end{array}$ & $\begin{array}{l}\text { Cull, translocation, inadequate herd } \\
\text { structure, premature weaning }\end{array}$ & $\begin{array}{l}\text { Slotow et al. (2000), Slotow } \\
\text { et al. (2001) }\end{array}$ \\
\hline $\begin{array}{l}\text { Venetia Limpopo Nature } \\
\text { Reserve, SA }\end{array}$ & $\begin{array}{l}\text { Intraspecific aggression, decreased } \\
\text { affiliative behaviour in a confined } \\
\text { group of juveniles, nervousness }\end{array}$ & $\begin{array}{l}\text { Cull, translocation, confinement, loss } \\
\text { of family, absence of mother figure }\end{array}$ & Garaï (1997), EMOA (2006) \\
\hline Addo National Park, SA & $\begin{array}{l}\text { Intraspecific hyper-aggression } \\
\text { and mortality }\end{array}$ & $\begin{array}{l}\text { Extreme population density, patterns } \\
\text { of irregular herd structure }\end{array}$ & $\begin{array}{l}\text { Whitehouse \& Hall-Martin } \\
\text { (2000), Whitehouse \& Kerley } \\
\text { (2002) }\end{array}$ \\
\hline Zambia & $\begin{array}{l}\text { Poor mothering and infant neglect, } \\
\text { intraspecific hyper-aggression }\end{array}$ & $\begin{array}{l}\text { Severe poaching, single } \\
\text { mother-infant, herd structure } \\
\text { breakdown }\end{array}$ & $\begin{array}{l}\text { Owens \& Owens (2005, } \\
\text { in press), Poole (1989) }\end{array}$ \\
\hline QENP Uganda & $\begin{array}{l}\text { Poor mothering and infant neglect, } \\
\text { intraspecific hyper-aggression }\end{array}$ & $\begin{array}{l}\text { Severe poaching, herd structure } \\
\text { breakdown }\end{array}$ & $\begin{array}{l}\text { Abe (1994), Nyakaana et al. } \\
\text { (2001), Poole (1989) }\end{array}$ \\
\hline Kenya & $\begin{array}{l}\text { Apathy, diminished social skills, } \\
\text { diminished mothering capabilities }\end{array}$ & $\begin{array}{l}\text { Poaching, culls, accidental } \\
\text { separations }\end{array}$ & D. Sheldrick, pers. comm. \\
\hline Pongola Game Reserve, SA & $\begin{array}{l}\text { Less vigilance towards offspring, no } \\
\text { birth helping }\end{array}$ & $\begin{array}{l}\text { Orphans, absence of experienced } \\
\text { adult females }\end{array}$ & EMOA (2006) \\
\hline
\end{tabular}




\section{Neuroethology of Elephant Atypical Behaviour}

In all cases described, individuals exhibiting abnormal behaviours were either translocated cull orphans, progeny of cull survivors, or reared under highly irregular herd structures. The hyper-aggressive cull orphans sustained multiple, major attachment disruptions and relational trauma (i.e. loss of mother and allomothers, premature weaning, witness to family deaths, herd dissolution, translocation; Slotow et al. 2001) during periods when critical patterning of brain development occurs (Schore 2003a). Neurobiologically, their hyper-aggression is consistent with an intense state of amygdala-hypothalamic sympathetic hyperarousal and a weakened higher right orbitofrontal inhibitory system associated with impaired developmental trauma (Rohlfs \& Ramirez 2006).

The absence of second phase all-male socialization is also likely to have been a significant factor leading to affective dysregulation. When males join other bulls, they learn how to navigate complex social interactions and regulate sensory-chemical systems of communication that inform appropriate behaviour and helps provide social order. This all-male developmental phase is coincident with a second phase of major mammalian brain re-organization (Spear 2000).

Relational trauma interferes with social learning that informs appropriate responses to environmental stimuli such as the ability to accurately detect species-shared emotional states and conspecific identities (Soltis et al. 2005). Processes of intraspecies hormone detection are affected through compromise of right hemisphere amygdala-hypothalamic connexions central to olfaction, emotional communication, and regulation of fear (Blonder et al. 1991; Small et al. 1999). Attempts by young male elephants to copulate with rhinoceroses are behaviours associated with extremely elevated states of central and autonomic arousal when sensory processing abilities become impaired and induce an inability to differentiate species-specific sexual signals from intraspecies aggressive pheromone signals (Rasmussen \& Krishnamurthy 2000). Behaviourally, such trauma-induced neuroendocrinological compromise is manifest as an abnormal fusion of affective, defensive, fear-motivated rage combined with elements of frustrated intense sexual drive. The adolescent elephants' elevated affective arousal states may have been particularly acute given the premature and sustained musth they entered in the absence of older bulls (Slotow et al. 2000). While it is not certain if all rhinoceros deaths were coincident with elephant musth, abnormal musth patterns and peaks in rhinoceroses mortality were correlated (Slotow $\&$ van Dyk 2001). The essential developmental roles that mature bulls fill was clearly demonstrated when older bulls introduced to the park quelled the young males' abnormally early musth cycles and interspecies aggression (Slotow et al. 2000).

In cases where interspecific aggression appears to be absent but intraspecific mortality is high, a different neuroendocrinological paradigm underlying the aggressive behaviour may be dominating. In these locations there has also been a history of social disruption, in particular affecting the male hierarchy, but unlike the other parks, these males are descendents, not necessarily direct recipients, of humancaused disturbances, namely severe hunting pressures and irregular herd demographics (Whitehouse \& Hall-Martin 2000). For example, there were only two mature bulls out of 11 elephants in the founder population in 1931 and one immature male. Between 1931 and 1938, while there were 18 births, by 1940 all three founder mature males had been killed. Offspring therefore received no older male socialization. Fence construction around the park perimeter in 1954 eliminated elephant-farmer conflict and the elephant population increased. However, while the herd was able to stabilize, an additional stressor might have been introduced with ever-decreasing habitat relative to population increases. Extraordinarily high levels of male mortality may therefore reflect a combination of factors that have altered normative social contexts: early trauma, abnormal attachment bonding, absence of male socialization, conditions of chronic, elevated stress created by inadequate habitat, and inability to avoid male-male conflict.

Developmental disruptions may have been particularly pronounced in males for another reason. Brain development occurs at a significantly slower rate in male mammals relative to females (Taylor 1969; Schore 1994) and therefore effects of developmental compromise accordingly are more pronounced. However, affective disorders in female elephants, while often less obvious (i.e. female internalizing vs. male externalizing dysregulation; Schore 2003a) have also been observed (Owens \& Owens 2005, in press; R. Slotow, pers. comm.). Deviations from normal elephant behaviour, namely, decreased maternal skills and infant neglect, have been noted particularly in areas where the loss of an older social stratum has been nearly complete (Table 1). The traumatic loss of the mother's psychobiological 
regulation during critical periods of infant female brain growth alters the developmental trajectory of successive generations (Champoux et al. 1992). Such compromise strikes at the heart of elephant culture where female natal herd functions as the central organizing process for elephant behavioural development. When the female matures there is increased likelihood of her exhibiting impaired maternal behaviour with her own offspring, as well as enduring deficits of stress regulation (Fleming et al. 1999; Meaney 2001).

\section{Conclusions}

We have used abnormal behaviour in wild elephants to illustrate how psychological theories of attachment and biological theories of developmental ecology can be used together to explain behavioural outcomes. Like psychology and neuroscience, ethology has shown an increased appreciation for the relationship between attachment processes and behavioural patterns. Bringing psychology and ethology together with insights from neuroscience provides one way to relate observed behaviour with models of endogenous (e.g. brain development) and exogenous (e.g. socio-ecological contexts) processes to better ascertain functional and proximal causation. This conceptual intersection profits all three disciplines.

For instance, only a few ethological studies have investigated the neuroethology of free-ranging social species. On the other hand, neuroscience has yet to fully explore the diversity of social systems involved in various species' social contexts that suggest models of brain development other than dyadic [e.g. Spectacled Parrotlet (Forpus conspiccillatus) adolescent crèches; Wanker et al. 1996].

An interdisciplinary perspective also contributes to help effect a much-called-for inclusion of behaviour into conservation (Linklater 2004). Given continued selective pressures by human disruptions that affect biology and behaviour in several ways (social learning, neurobiology and genetics), it is worth considering long-term outcomes. In addition to sharing basic corticolimbic structures with other mammals, the African elephant has an extremely large and convoluted hippocampus that is responsible for mediating long-term social memory (Hakeem et al. 2005). Disruptions affecting brain mechanisms central to processing socio-ecological knowledge thus affect how well successive generations are able to retain, represent, process and communicate complex social information necessary for elephant group survival. We speculate that because of compromised maturation of the right brain through relational trauma that capture and captivity engender, some elephants will not show evidence of complex behaviours such as self-recognition (Plotnik et al. 2006): a possible explanation for the apparent absence of this ability in some test subjects.

This raises another important point concerning phenotypic plasticity, or its lack, and the ability for elephant culture to re-stabilize. Elephant conservation measures are beginning to be revised to prevent disruptions to traditional developmental patterns whenever possible (e.g. family units vs. single infant translocation; Litoroh et al. 2001; restoration of social strata and age-structures; Slotow et al. 2000). However, artificial reconstruction of normative social contexts has often failed to recreate much of the necessary social processes that rely so heavily on cross-generational fidelity (Garaï et al. 2004). While the introduction of older bull elephants attenuated symptoms at one park, this approach had limited success at another (Slotow et al. 2000, 2001; Druce et al. in press).

In the light of developmental neuroethology, this outcome is not surprising. While there is some evidence of reversibility, early attachment failures without adequate compensatory social structures for recovery are associated with a high risk for later disorders (Perry \& Azad 1999). The persistence of stress effects in the neurobiological substrate predicts that its symptoms are likely to re-surface when stress or deprivation levels increase beyond a certain point (Schore 2003a). Sudden changes in behaviour or 'problem animal' or 'rogue' attacks that are increasingly noted are consistent with the aetiology of posttraumatic stress disorder 'flashbacks' (Bradshaw et al. 2005).

There is a further concern that selection for asocial heritable traits in the absence of normal socialization structures may increase under such conditions of high stress and social disruption. Between 5\% and $10 \%$ of a natural population in rhesus monkeys exhibited heritable tendencies for stress-sensitivity that are correlated with chronic deficits in metabolic serotonin, a neurotransmitter involved in stress modulation. Under conditions of trauma or compromised bonding, these tendencies fail to be ameliorated and result in hyper-aggressive behaviour (Suomi 2004): evidence suggesting that genetic selection processes already affecting elephant populations with skewed population off-take may impose an added risk.

As perturbing as the data from Africa (and increasingly, Asia) are, the altered behaviours of wild 
elephants have performed a significant task. They have opened a door that brings ethological, psychological and neurobiological models together to gain deeper insights into the relationships between developmental contexts and behaviour outcomes. The new-found facility to extend bidirectional inference across species brings an increased coherency to behavioural research, something that Tinbergen would have surely appreciated.

\section{Acknowledgements}

The authors would like to thank O. Mein Gans, E. Lawino Abe, D. Durham, M. Garai, C. Moss, J. Poole, D. Sheldrick, R. Slotow, the editor and three reviewers for comments on previous drafts.

\section{Literature Cited}

Abe, E. L. 1994: Behavioral ecology of elephant survivors in Queen Elizabeth National Park, Uganda. PhD Dissertation, Cambridge Univ., Cambridge, UK.

Adolphs, R. F., Gosselin, T. W., Buchanan, D., Tranel, P., Schyns, P. \& Damasio, A. R. 2004: A mechanism for impaired fear recognition after amygdala damage. Nature. 1433, 68-72.

AERP 2006: Amboseli Elephant Research Project. LongTerm Records. Amboseli, Kenya.

Aleper, D. \& Moe, S. R. 2006: The African savannah elephant population in Kedepo Valley National Park, Uganda: changes in size and structure from 19672000. Afr. J. Ecol. 44, 157-164.

Bateson, P. 2003: The promise of behavioural biology. Anim. Behav. 65, 11-17.

Berridge, K. C. 2003: Comparing the motional brains of humans and other animals. In: Handbook of Affective Sciences (Davidson, R. J., Scherer, K. R. \& Hill Goldsmith, H., eds). Oxford Univ. Press, Oxford, pp. 23-45.

Blanchard, D. C. \& Blanchard, R. J. 1984: Affect and aggression: an animal model applied to human behavior. Adv. Study Aggress. 1, 1-62.

Blonder, L. X., Bowers, D. \& Heilman, K. M. 1991: The role of the right hemisphere in emotional communication. Brain 114, 1115-1127.

Bowlby, J. 1969: Attachment. Hogarth Press, London.

Bradshaw, G. A. \& Finlay, B. L. 2005: Natural symmetry. Nature 435, 149.

Bradshaw, G. A. \& Sapolsky, R. M. 2006: Mirror, mirror. Am. Sci. Nov/Dec, 487-489.

Bradshaw, G. A., Schore, A. N., Poole, J. H., Moss, C. J. \& Brown, J. L. 2005: Elephant breakdown. Nature 433, 807.

Brown, J. L., Wielebnowski, N. \& Cheeran, J. C. 2005: Evaluating stress and wellbeing in elephants: are we doing all we can do to make sure elephants are well cared for? In: Never Forgetting: Elephants and Ethics (Wemmer, C. \& Christen, C., eds). Johns Hopkins Univ. Press, Baltimore, MD, pp. 56-61.

Burke, T. 2005: The effect of human disturbance on elephant behaviour, movement dynamics, and stress in a small reserve: Pilanesberg National Park. Master's Thesis, Univ. of KwaZulu-Natal, Durban, South Africa.

Champoux, M., Byrne, E., DeLizio, R. \& Suomi, S. J. 1992: Motherless mothers revisited: rhesus maternal behavior and rearing history. Primates 33, 251-255.

Chiron, C., Jambaque, I., Nabbout, R., Lounes, R., Syrota, A. \& Dulac, O. 1997: The right brain hemisphere is dominant in human infants. Brain 120, 1057-1065.

Cirulli, F., Berry, A. \& Alleva, E. 2003: Early disruption of the mother-infant relationship: effects on brain plasticity and implications for psychopathology. Neurosci. Behav. Rev. 27, 73-82.

Curley, J. P. \& Keverne, E. P. 2005: Genes, brains, and mammalian social bonds. Trends Ecol. Evol. 20, $561-567$.

Davidson, R. J., Scherer, K. R. \& Hill Goldsmith, H. (eds) 2003: The Handbook of Affective Neuroscience. Oxford Univ. Press, Oxford.

Dettling, A. C., Feldon, J. \& Pryce, C. R. 2002: Repeated parental deprivation in the infant Common Marmoset (Callthrix, Primates) and analysis of its effects on early development. Biol. Psychiatry 52, 1037-1046.

Druce, H., Pretorius, K., Druce, D. \& Slotow, R. 2006: The effects of mature bull introductions on resident bull's group size and musth periods: Phinda Private Game Reserve, South Africa. S. Afr. J. Wildl. Res. 36(2), p. 133-137.

Dunbar, R. I. M. 1998: The social brain hypothesis. Evol. Anthropol. 6, 178-190.

EMOA 2006: Database. Elephant Managers and Owners Association, South Africa. Available at: http://www. emoa.org.za.

Fleming, A. S., O’Day, D. H. \& Kraemer, G. W. 1999: Neurobiology of mother-infant interactions: experience and central nervous system plasticity across development and generations. Neurosci. Biobehav. Rev. 23, $673-685$.

Foley, C. A. H., Papageorge, S. \& Wasser, S. K. 2001: Nonreproductive stress and measures of socio-ecological pressures in free-ranging African elephants. Conserv. Biol. 15, 1134-1142.

Fowler, G. S. 1999: Behavioral and hormonal responses of Magellanic penguins (Spheniscus magellanicus) to tourism and nest site visitation. Biol. Conserv. 90, 143-149.

Francis, D. J., Diorio, D., Liu, D. \& Meaney, M. J. 1999: Nongenomic transmission across generations of maternal behaviour and stress repsonses in the rat. Science 286, 1155-1158. 
Garaï, M. E. 1997: The development of social behavior in translocated juvenile elephants (Loxodonta africanus). PhD Dissertation, Univ. of Pretoria, Pretoria, South Africa.

Garaï, M. E., Slotow, R. Carr, D. \& Reilly, B. 2004: Elephant reintroductions to small fenced reserves in South Africa. Pachyderm 37, 28-36.

Goldstein, M. H., King, A. P. \& West, M. J. 2003: Social interaction shapes babbling: testing parallels between birdsong and speech. Proc. Natl Acad. Sci. U.S.A. 100, 8030-8035.

Ha, J. C., Robinette, R. L. \& Sackett, G. P. 1999: Social housing and pregnancy outcome in captive pigtailed macaques. Am. J. Primatol. 47, 153-163.

Hakeem, A. Y., Hof, O. R., Sherwood, C. C., Switzer, R. C., III \& Allman, J. M. 2005: Brain of the African elephant (Loxodonta africana): neuroanatomy from magnetic resonance images. Anat Rec A Discov Mol Cell Evol Biol 287A, 1117-1127.

Hanks, J. 1979: A Struggle for Survival: the Elephant Problem. Struik, Cape Town, South Africa.

Hausfater, G. \& Blaffer Hrdy, S. (eds) 1984: Infanticide: Comparative and Evolutionary Perspectives. Aldine, New York.

Heim, C. \& Nemeroff, C. B. 1999: The impact of early adverse experiences on brain systems involved in the pathophysiology of anxiety and affective disorders. Biol. Psychiatry 46, 1509-1522.

Helmeke, C., Ovtscharoff, W., Jr, Poeggel, G. \& Braun, K. 2001: Juvenile emotional experience alters synaptic inputs on pyramidal neurons in the anterior cingulate cortex. Cereb. Cortex 2001 11, 717-727.

Henry, J. P. 1993: Psychological and physiological responses to stress: the right hemisphere and the hypothalamo-pituitary-adrenal axis, an inquiry into problems of human bonding. Integr. Physiol. Behav. Sci. 28, 369-387.

Ichise, M., Vines, D. C., Gura, T., Anderson, G. M., Suomi, S. J., Higley, J. D. \& Innis, R. B. 2006: Effects of early life stress on $\left[{ }^{11} \mathrm{~A}\right]$ DASB positron emission tomography imaging of serotonin transporters in adolescent peer- and mother-reared rhesus monkeys. J. Neurosci. 26, 4638-4643.

Jarvis, E. et al. 2005: Avian brain and a new understanding of vertebrate brain evolution. Nat. Rev. Neurosci. 6, 151-159.

Karten, Y. J. G., Olariu, A. \& Cameron, H. A. 2005: Stress in early life inhibits neurogenesis in adulthood. Trends Neurosci. 28, 171-172.

Ladd, C. O., Huot, R. L., Thrivikraman, K. V., Nemeroff, C. B. \& Plotsky, P. 2004: Long-term adaptations in glucocorticoid receptor and mineralocorticoid receptor mRNA and negative feedback on the hypoathalamopituitary-adrenal axis following maternal separation. Biol. Psychiatry 55, 367-375.
Lee, P. C. 1987: Allomothering among African elephants. Anim. Behav. 35, 278-291.

Lee, P. C. \& Moss, C. N. 1999: The social context for learning and behavioural development among wild African elephants. In: Mammalian Social Learning (Box, H. O. \& Gibson, K. R., eds). Cambridge Univ. Press, Cambridge, pp. 102-125.

Linklater, W. L. 2004: Wanted for conservation research: behavioral ecologists with a broader perspective. BioScience 54, 352-360.

Litoroh, M., Omondi, P., Bitok, E. \& Wambwa, E. 2001: Two successful elephant translocations in Kenya. Pachyderm 31, 74.

Lyons, D. M., Afarian, H., Shatzberg, A. F., Sawyer-Glover, A. \& Mosley, M. E. 2002: Experience-dependent asymmetric variation in primate prefrontal morphology. Behav. Brain. Res. 136, 51-59.

McComb, K. C., Moss, C., Durant, S., Sayialel, S. \& Baker, L. 2001: Matriarchs as repositories of social knowledge. Science 292, 491-494.

McCormack, K., Sanchez, M. M., Bardi, M. \& Maestripieri, D. 2006: Maternal care patterns and behavioral development of rhesus macaque abused infants in the first 6 months of life. Dev. Psychobiol. 48, 537-540.

Meaney, M. J. 2001: Maternal care, gene expression, and the transmission of individual differences in stress reactivity across generations. Ann. Rev. Neurosci. 24, $1161-1192$.

Meaney, M. J. \& Szyf, M. 2005: Maternal care as a model for experience-dependent chromatin plasticity? Trends Neurosci. 28, 456-463.

Mesnick, S. L. 1997: Sexual alliances: evidence and evolutionary implications. In: Feminism and Evolutionary Biology: Boundaries, Intersections and Frontiers (Gowaty, P. A., ed.). Chapman \& Hall, New York, pp. 207-260.

Morris, J. S., Ohman, A. \& Dolan, R. J. 1999: A subcortical pathway to the right amygdala mediating "unseen" fear. Proceedings of the National Academy of Sciences, 96(4), 1680-1685.

Nyakaana, S., Abe, E. L., Arctander, P. \& Siegismund, H. R. 2001: DNA evidence for elephant social behaviour breakdown in Queen Elizabeth National Park, Uganda. Anim. Conserv. 4, 231-237.

Owens, D. \& Owens, M. 2005: Comeback kids: elephant "single moms" are struggling to recreate family life after the traumatic years of poaching. Nat. Hist. July, 34.

Owens, D. \& Owens, M. in press: Early age reproduction in female elephants after severe poaching. Afr. J. Ecol., in press.

Panksepp, J. 1998: Affective Neurosciences: the Foundations of Human and Animal Emotions. Oxford Univ. Press, Oxford.

Perry, B. D. \& Azad, I. 1999: Post-traumatic stress disorders in children and adolescents. Curr. Opin. Pediatr. 11, $121-132$. 
Plotnik, J. M., de Waal, F. B. M. \& Reiss, D. 2006: Selfrecognition in an Asian elephant. Proc. Natl Acad. Sci. U.S.A. 103, 17053-17057.

Poeggel, G., Nowicki, L. \& Braun, K. 2005: Early social environment interferes with the development of $\mathrm{NADPH}$-diaphorase-reactive neurons in the rodent orbital prefrontal cortex. Int. J. Neurobiol. 62, 42-46.

Poole, J. H. 1989: The effects of poaching on the age structures and social and reproductive patterns of selected East African elephant populations. In: The Ivory Trade and the Future of the African Elephant. Volume II Technical Reports. Prepared for the 7th CITES Conference of the Parties. Nairobi, Kenya, pp. 1-73.

Rasmussen, L. E. L. \& Krishnamurthy, V. 2000: How chemical signals integrate Asian elephant society: the known and the unknown. Zoo Biol. 19, 405.

Rohlfs, P. \& Ramirez, J. M. 2006: Aggression and brain asymmetries: a theoretical overview. Aggress. Violent Behav. 11, 283-297.

Ronsaville, D. S., Municchi, G., Laney, C., Cizza, G., Meyer, S. E., Haim, A., Radke Yarrow, M., Chrousos, G., Gold, P. W., Martinez, P. E. 2006: Maternal and environmental factors influence the hypothalamic-pituitary-adrenal axis response to corticotropin-releasing hormone infusion in offspring of mothers with or without mood disorders. Dev. Psychopathol. 18, 173-194.

Sapolsky, R. 2004: Mothering style and methylation. Nat. Neurosci. 7, 791-792.

Schore, A. N. 1994: Affect Regulation and Origin of the Self: the Neurobiology of Emotional Development. Erlbaum, Mahwah, NJ.

Schore, A. N. 2003a: Affect Dysregulation and Disorders of the Self. W.W. Norton, New York.

Schore, A. N. 2003b: Affect Regulation and the Repair of the Self. W.W. Norton, New York.

Siegel, D. J. 1999: The Developing Mind: Toward a Neurobiology of Interpersonal Experience. Guilford Press, New York.

Silk, J. B., Alberts, S. C. \& Altmann, J. 2003: Social bonds of female baboons enhance infant survival. Science 302, 1231-1234.

Slotow, R. \& van Dyk, G. 2001: Role of delinquent young "orphan" male elephants in high mortality of white rhinoceros in Pilanesberg National Park, South Africa. Koedoe 44, 85-94.

Slotow, R., van Dyk, G., Poole, J. \& Klocke, A. 2000: Older bull elephants control young males. Nature $\mathbf{4 0 8}$, 425-426.

Slotow, R., Balfour, D. \& Howison, O. 2001: Killing of black and white rhinoceroses by African elephants in Hluhluhe-Umfolozi, South Africa. Pachyderm 31, $14-20$.

Small, D. N., Zald, D. H., Jones-Gotman, M., Zatorre, R. J., Pardo, J. V., Frey, S. \& Petrides, M. 1999: Human corti- cal gustatory areas: a review of functional neuroimaging data. Neuroreport 10, 7-14.

Soltis, J., Leong, K. \& Savage, A. 2005: African elephant vocal communication II: rumble variation reflects the individual identity and emotional state of callers.

Anim. Behav. 70, 589-599.

Spear, L. P. 2000: The adolescent brain and age-related behavioral manifestations. Neurosci. Biobehav. Rev.

24, 417-463.

Stamps, J. 2003: Behavioural processes affecting development: Tinbergen's fourth question comes of age. Anim. Behav. 66, 1-13.

Stuss, D. T. \& Alexander, M. P. 1999: Affectively burnt in: one role of the right frontal lobe. In: Memory, Consciousness, and the Brain (Tulving, E., ed.). The Talin Conference, Psychology Press, Philadelphia, PA, pp. 215-227.

Sullivan, R. M. \& Dufresne, M. M. 2006: Mesocortical dopamine and HPA axis regulation: role of laterality and early environment. Brain. Res. 1076, 49-59.

Suomi, S. J. 2004: How gene-environment interactions can influence emotional development in Rhesus monkeys. In: Nature and Nurture: the Complex Interplay of Genetic and Environmental Influences on Human Behaviour and Development (Garcia-Coll, C. E., Bearer, L. \& Lerner, R. M., eds). Lawrence Erlbaum, Mahwah, NJ, pp. 35-51.

Taborsky, M. 2006: Ethology into a new era. Ethology 112, $1-6$.

Tang, A. C., Reeb, B. C., Romeo, R. D. \& McEwen, B. S. 2003: Modification of social memory, hypothalamicpituitary-adrenal axis, and brain asymmetry by neonatal novelty exposure. J. Neurosci. 23, 8254-8260.

Taylor, D. C. 1969: Differential rates of cerebral maturation between sexes and between hemispheres. Lancet 2, 140-142.

Tinbergen, N. S. 1951: The Study of Instinct. Clarendon Press, London.

Tinbergen, N. S. 1963: On aims and methods of ethology. Z. Tierpsychol. 20, 410-433.

Topal, J., Gacsi, M., Miklosi, A., Viranyi, Z., Kubinyi, E. \& Csanyi, V. 2005: Attachment to humans: a comparative study on hand-reared wolves and differently socialized dog puppies. Anim. Behav. 70, 1367-1375.

Vallortigara, G. \& Rogers, L. J. 2005: Survival with an asymmetrical brain: advantages and disadvantages of cerebral lateralization. Behav. Brain Sci. 28, 575-633.

Wanker, R., Bernate, L. C. \& Franck, D. 1996: Socialization of spectacled parrotlets Forpus conspicillatus: the role of parents, crèches and sibling groups in nature. J. Ornithol. 137, 447-461.

West, M. J. \& King, J. A. 1987: Settling nature and nurture into an ontogenetic niche. Dev. Psychobiol. 20, $549-562$. 
West, M. J., King, J. A. \& White, D. 2003: The case for developmental ecology. Anim. Behav. 66, $617-622$.

Whitehouse, A. M. \& Hall-Martin, A. J. 2000: Elephants in Addo Elephant National Park, South Africa: reconstruction of the population's history. Oryx 34, $46-55$.

Whitehouse, A. M. \& Kerley, G. I. H. 2002: Retrospective assessment of long-term conservation management of elephants in Addo Elephant National Park, South Africa. Oryx 36, 243-248.

Wiedenmayer, C. P. 2004: Adaptations or pathologies? Long-term changes in brain and behaviour after a single exposure to severe threat. Neurosci. Behav. Rev.

28, $1-12$.

Wrangham, R. W., Wilson, M. L. \& Muller, M. N. 2006: Comparative rates of violence in chimpanzees and humans. Primates 47, 14-26. 